\title{
Predictability of Stock Returns on the Dhaka Stock Exchange
}

\author{
Yub Raj Dhungana, PhD \\ Associate Professor, Tribhuvan University \\ Email: dhunganayr@gmail.com
}

\begin{abstract}
The study examines the predictability of index returns on the Dhaka stock market within the framework of the weak-form efficient market hypothesis using historical daily returns for a period of $1^{\text {st }}$ June, 2014 to $29^{\text {th }}$ May, 2020. The Jarque-Bera statistics test explored the return distribution of Dhaka Stock Exchange is non-normal. The random walk hypothesis (RWH) was tested using autocorrelation test, runs test, unit root tests (Augmented Dickey-Fuller (ADF) and, Phillip-Perron (PP) test) and variance ratio test. The results explored that all tests rejected the random walk hypothesis required by the weak-form efficient market hypothesis. This provides empirical basis to infer that the DSE is inefficient at weak-form and stock return can be predicted. The rejection of the $R W H$ on a daily basis is possibly an indication that the weak-form inefficient characteristic of the DSE is not sensitive to return frequency.
\end{abstract}

Keywords: weak-form efficiency, random walk, Dhaka Stock Exchange, index returns, autocorrelation test, runs test, unit root tests, variance ratio test

\section{Introduction}

The Efficient Market Hypothesis (EMH) has assumed a significant role in financial theory, evidenced by the multitude of research aiming to test its suitability, validity, and the insights it presents (Mlambo \& Biekpe, 2007). According to (Levine, 1997)more liquid markets can create long-term investments through the crucial function of financial intermediation. Nonetheless, the ability of the stock market to present itself as an effective financial intermediator and assure investors of fair returns is contingent on efficiency.

Fama(1970) described an efficient market as one in which the price of a share already contains all there is to know about it. He explains further that for a market to be efficient, successive price changes in individual securities must be independent or must exhibit what he termed a "random walk pattern." Specifically, share prices and returns adjust rapidly at the arrival of new information, meaning they fully reflect all available data and should therefore follow a random walk process. Intuitively, market efficiency prevents arbitraging and accumulating abnormal profits (profits that exceed the market premium). A simple strategy of buying and holding is as good as any more complicated technical 
and mechanical procedure for timing purchase and sales. Gupta and Gedam (2014) granted that prices fully reflect available information and anticipated risk, the only way an investor can possibly maximize higher returns is by purchasing riskier investments. These perceptions mainly inspired the empirical interest and investigation into the efficiency of stock markets that continued over a long period and contained of a vast amount of research conducted using multitude statistical approaches. These studies have mainly focused on developed markets, leaving a prominent research gap in emerging markets.

The Ghana Stock Exchange (GSE) has recently seen an unprecedented growth in market capitalization, volume traded, and value. Similarly, the Ghana Stock Exchange index returns has also observed significant upgrade over the years, a situation that could apparently be explained by investor confidence in the stock exchange. Despite these developments, there is a noticeable lack of empirical attempts at ascertaining the level of market efficiency, a concept that requires examination. Simon and Laryea (2004) deplores that this research dummy may have contributed to the importance of African markets to attract huge equity investments similar to those obtained by Asian and American economies. This study aims to examine the weak-form efficiency of the DSE within the framework of the random walk proposition. The study considers the daily index returns of all firms listed on the market since its inception. The study explores empirical evidence that is representative of the entire market. The anticipation is that the DSE is efficient across the daily index returns. This study is quite different with existing studies in a countless of ways. This study combines parametric and non-parametric methods to test the validity of the EMH on the daily return series. This study captures contemporary developments that may have bearing on market predictability.

\section{Literature Review}

The efficient market hypothesis was propounded by Fama (1970) and popularized in his famous review paper entitled Efficient Capital Markets: A Review of Theory and Empirical Work. He suggests that the price in a market always fully reflect all available information is called efficient market. The divination of the Efficient Market Hypothesis at any given time, a security price fully incorporates all available information. Peculiarly, stock prices adjust quickly to new information to certify that the making price reflects it. Accepting the different private and public information, the EMH categorizes exhibiting strong, semi-strong, and weak-form efficiency. Strong-form efficiency summarizes both private and publicly available information. The semi-strong form of efficiency centers only on public information, whereas weak-form efficiency accepts that future prices are random in nature and cannot be predicted, but permits short-run excess. The three forms 
of stock market efficiency disprove the possibility of long-run excess returns to investors. Okpara (2010) appraised the random walk proposition on the Nigerian Stock Exchange (NSE) by using the Generalized Autoregressive Conditional Heteroscedasticity $(\mathrm{GARCH})$ model. The researcher explored that the NSE returns were weak-form efficient for the period of 1984 to 2006 and that the market was generally weak-form efficient. Although, he found the confirmation of volatility clustering, indicating inefficiency in selected specific periods including the period of 2000 to 2006 of the Nigerian capital market in 1995. Gimba (2012) also appraised the random walk proposition on the NSE daily and weekly return series for the period of 2005 to 2009 , would follow a random walk. He concluded that the Nigerian stock market was not efficient in the weak form.

Akinkugbe (2005) applied autocorrelation, the Phillips-Perron (P-P) and Augmented Dickey-Fuller (ADF) unit root tests to appraise the efficiency of the Botswana stock market using 738 weekly closing prices. He found that the market was weak form of efficient and semi-strong forms. In an empirical study of South Africa, Egypt, Ghana, and Mauritius, Simon and Laryea (2004) used Kolmogrov-Smirnov (KS) goodness of fit test, the runs test, the autocorrelation test, and the variance ratio test to appraise the efficiency of their stock markets. They found that while the South African market followed a random walk, the markets of Egypt, Ghana, and Mauritius were weak-form inefficient. Osamah and Ding (2007) attained a study applying the variance ratio test to appraise the efficiency of stock markets in the Middle East and North Africa (MENA). Their findings accept the random walk hypothesis. So the study was indicating that the selected MENA markets were weak-form of efficient. Another study specifically regarding Ghana by Osei (2002) reported that the market generally followed an up-anddown pattern basis of good and bad news, simultaneously. He concluded that the up-anddown phenomenon was at variance with the EMH. Ntim, Opong, and Dunbolt (2007) also assessed the efficiency of the GSE for the period of November 1990 to December 2005. They applied the Lo-MacKinlay (LOMAC) and the Wright variance ratio tests and explored mixed results. The LOMAC test rejected the random walk hypothesis, but the Wright test results were indecisive. They explored the result that the GSE was not weakform efficient based on the LOMAC results. Using daily stock returns for the period of 2006 to 2011, (Mensah, Adom, \& Pomaa-Berko, 2014) assess to find if automation improved efficiency on the GSE through the unit root test, variance ratio test, and the GARCH model $(1,1)$. They found the result of weak-form inefficiency before and after automation. Gilani (2014) found a weak-form efficiency of the Islamabad Stock Exchange (ISE) for the period of January 2013 to December 2013. To assess the stock market efficiency of the Islamabad Stock exchange, by using different statistical 
techniques to analyze the weekly ISE-10 share index. This study applies the famous tests like run tests and the ADF test to check the Weak form efficiency of ISE. The study also concentrated on the random walk behavior of the stock market of Islamabad. Autocorrelation test and Run test explored market inefficiency at specific periods but ADF test showed weak form of market efficiency.

Ojo and Azeez (2012) assessed the presence of the strong-form efficient market hypothesis in the Nigerian stock market for the period of 1986 to 2010. The empirical analysis was conducted employing the Autoregressive Conditional Heteroscedasticity $(\mathrm{ARCH})$ and Generalized Autoregressive Conditional Heteroscedasticity (GARCH) models. The empirical results revealed that the Nigerian capital market was weak-form efficient.

Potocki and Swist (2012) examined the strong form of market informational efficiency, based on the assumption that the institutions issuing recommendations have access to information inaccessible to the community of investors. The research sample consists of 3,270 recommendations produced between 1 January 2005 and 31 March 2010 by 63 financial entities regarding companies making up the WIG 20 index. The results disclosed the evidence for the efficient market hypothesis that the strong form efficiency is characteristic of the WIG 20 index shares listed on the Warsaw Stock Exchange.

Oladapo and Ayowole (2013) investigated empirically the efficiency of the Nigerian Stock Market to test whether professionally managed funds beat the market index or not. In this research the monthly returns of five banks over the period 2007 to 2011 were used. The "market model" for estimating residuals were used to test the efficiency of the Nigerian Stock Market. The excessive return of the professionally managed portfolio is found to be insignificantly different from zero. The Nigerian Stock Market discloses the result of strong form of efficiency.

\section{Methodology, Data \& Hypothesis}

Daily data of Dhaka Stock Exchange for the period of $1^{\text {st }}$ June, 2014 to $29^{\text {th }}$ May, 2020 were used for analysis. All the data were taken from the official website of Dhaka Stock Exchange. The study employed Auto-correlation test, Unit root test, Runs test and Variance ratio test to assess the random walk proposition on the DSE. For statistical test SPSS and Eviews software are employed.

\section{Auto Correlation Test}

This study applied the Ljung and Box autocorrelation test to establish whether DSE returns exhibited serial dependence. The Ljung-Box Q-statistics assume a null 
hypothesis (H0) that all autocorrelations equal zero. Particularly, the non-appearance of correlation in successive returns is an indication of randomness or stochastic series. Thus, a significant Q-statistic rejects the null hypothesis and indicates that there is predictability in future returns or the series is not efficient in weak-form (not random).

\section{Runs Test}

A runs test is another common approach to test for statistical independencies. The runs test is a non-parametric test that is designed to examine whether successive price changes are independent. The test is based on the premise that if a series of a data is random, the observed number of runs in the series should be close to the expected number of runs.

\section{Unit Root Test}

The random walk requires the presence of a unit root (non-stationary) in the series, this study applied two unit root test procedures namely the Augmented Dickey-Fuller (ADF) and Phillip-Perron (PP) tests.

\section{Variance Ratio Test}

The variance ratio test has gained resounding empirical popularity in recent years. The VR methodology entails testing the random walk hypothesis (RWH) against stationary alternatives by exploiting the fact that the variance of random walk increments is linear in all sampling intervals.

\section{Hypothesis}

The objective of this research paper is to examine the predictability of stock returns on the Dhaka Stock Exchange. Therefore, the hypothesis to be tested is:

H0: Future return is predictable

H0: There is a presence of unit root (non- stationary).

H0: Daily index return follows a martingale.

\section{Empirical Results and Findings}

\section{Descriptive Statistics}

The descriptive statistics of returns on the DSE indices are presented in Table 1. The Skewness of the return series was positive. This implied that the asymmetric tail of returns on the DSE extended more towards positive values, which indicated a significant probability of large gains and a small probability of losses. The kurtosis explored significant positive excess kurtosis, implying leptokurtic (fat-tailed) distribution. The 
Skewness and the leptokurtic returns were an indication of non-normality distribution of the returns on the DSE. The non-normal distribution of the daily return series was further affirmed by the significance of the Jarque-Bera statistics.

Table 1

Descriptive Statistics of Index Return

\begin{tabular}{ll}
\hline Measures & Daily Index Return \\
\hline Mean & $-4.02 \mathrm{e}-05$ \\
Median & $4.33 \mathrm{e}-05$ \\
Maximum & 0.102945 \\
Minimum & -1.065152 \\
Std. Dev. & 0.008231 \\
Skewness & 1.185402 \\
Kurtosis & 26.5501 \\
Jarque-Bera & 32913.4 \\
Probability & 0 \\
Observations & 1410 \\
\hline
\end{tabular}

\section{Result of Autocorrelation Test}

The results of autocorrelation tests for daily index returns are presented in Table 2. Negative autocorrelations suggested that sequential returns were inversely correlated, showing that stock returns were possibly floating towards mean values rather than floating away. Positive autocorrelations suggested that sequential returns were possibly sustained, indicating that return changes might carry momentum.

The autocorrelation coefficients and the Ljung-Box Q statistic are shown for 16 lags. The results explored the probability is less than the $5 \%$ level of significance of all lag. Thus, the null hypothesis of random walk (RW) was rejected and the daily index return data series were concluded to exhibit no weak-form market efficiency, a further declaration of the predictability of returns on the DSE. So, DSE return can be predicted. 
Table 2

Autocorrelation Test

\begin{tabular}{llllll}
\hline \multirow{2}{*}{ Lag } & \multirow{2}{*}{ Autocorrelation } & Std. Error & \multicolumn{3}{c}{ Box-Ljung Statistic } \\
\cline { 4 - 6 } & & & Value & df & Sig. $^{\text {b }}$ \\
\hline 1 & 0.175 & 0.027 & 43.044 & 1 & 0 \\
2 & -0.031 & 0.027 & 44.408 & 2 & 0 \\
3 & 0.008 & 0.027 & 44.503 & 3 & 0 \\
4 & 0.032 & 0.027 & 45.92 & 4 & 0 \\
5 & 0.091 & 0.027 & 57.562 & 5 & 0 \\
6 & 0.078 & 0.027 & 66.273 & 6 & 0 \\
7 & -0.079 & 0.027 & 75.237 & 7 & 0 \\
8 & -0.064 & 0.027 & 81.024 & 8 & 0 \\
9 & -0.024 & 0.027 & 81.852 & 9 & 0 \\
10 & 0.012 & 0.027 & 82.043 & 10 & 0 \\
11 & 0.035 & 0.027 & 83.761 & 11 & 0 \\
12 & 0.035 & 0.026 & 85.519 & 12 & 0 \\
13 & 0 & 0.026 & 85.519 & 13 & 0 \\
14 & -0.005 & 0.026 & 85.559 & 14 & 0 \\
15 & 0.004 & 0.026 & 85.579 & 15 & 0 \\
16 & -0.033 & 0.026 & 87.114 & 16 & 0 \\
\hline
\end{tabular}

\section{Results of Runs Test}

The runs test assumed that runs did not follow any systematic pattern of occurrence or there was no predictable pattern of run occurrence. Table 3 presents the results of the runs test for daily DSE index returns.

Table 3

Runs Test

\begin{tabular}{ll}
\hline Test value & 0.000043 \\
Total cases & 1410 \\
Z-statistics & -5.381 \\
Probability & 0 \\
\hline
\end{tabular}

The Z-statistics associated with the daily return series was negative of 5.381 and rejecting the null hypothesis (test is significant). In the same stratification, the size of the 
Z-values was higher than the critical values at 5\%, declaring the absence of randomness in the returns. This disproved the fundamental assumption of the test that runs did not follow a systematic pattern and returns can be predicted.

\section{Result of Unit Root Test}

The results of the ADF and Phillip-Perron (PP) tests for daily index returns are shown in Table 4 . The results showed that the respective $p$-values of the daily return series in the four tests were less than 0.05 at $5 \%$ significance level. This implied that the data sets were stationary and thus the null hypothesis of unit root was rejected in all tests. Given that weak-form market efficiency required randomness in the returns, the series must exhibit non-stationarity. In the same stratification, the sizes of the Z-values of two tests were higher than the critical values at $5 \%$, declaring the absence of non-stationarity in the returns and returns can be predicted.

Table 4

Unit Root Test

\begin{tabular}{lll}
\hline Tests & Z-statistics & Probability \\
\hline ADF test & -19.77853 & 0.00000 \\
PP test & -344.5469 & 0.00000 \\
\hline
\end{tabular}

\section{Result of Variance Ratio Test}

The variance ratio test in this study was conducted under the null hypothesis that daily index return follow a martingale (followed an RW), the variance ratios were expected to be less than one. Individual and joint variance ratio tests were conducted for multiples of $2,4,8$ and 16 days.

Table 5

Variance Ratio Test

\begin{tabular}{lll}
\hline Tests & Z-statistics & P-value \\
\hline Joint test & 4.18492 & 0.0001 \\
Individual test: & - & - \\
Periods & & \\
2 & -3.456853 & 0.0005 \\
4 & -4.18492 & 0 \\
8 & -3.873834 & 0.0001 \\
16 & -3.168777 & 0.0015 \\
\hline
\end{tabular}


The individual VR results in this study were reported under the assumptions of heteroscedasticity. The results of both individual and joint variance ratio test (Table 5) under the null hypothesis that stock returns does not follow a martingale (RW) showed the probability is less than 0.05 and statistical value is higher than the critical value at $5 \%$ level of significance. This implies that the random walk hypothesis is rejected and that the return indexes are not weak-form efficient. This means that the DSE returns does not follow a systematic pattern and could be predicted with historical return values.

\section{Conclusions and Implications}

This paper examines the predictability of stock returns on the Dhaka Stock Exchange. The study employed four different tests, Auto-correlation test, Unit root test (Augmented Dickey-Fuller (ADF) and Phillip-Perron (PP) tests), Runs test and Variance ratio tests and find similar results. The results of these tests find that these markets are predictable (not weak form efficient). So the implication of rejection of weak form efficiency for investors is that investors can better predict the stock price movements, by holding a well-diversified portfolio while investing in the Dhaka Stock Exchange market. Inefficient market also creates a compatible framework for insider trading, and it is prone to over-inflated prices and speculation. But this study is unable to consider the exploitation may be profitable, given that inefficiency also drives up transaction cost. For future research, using a computationally more efficient model like generalized autoregressive conditional heteroskesdasticity $(\mathrm{GARCH})$ could be more useful and weekly, monthly and yearly index could be used for the study.

\section{References}

Akinkugbe, O. (2005). Efficiency in Botswana Stock Exchange: An Empirical Analysis. The Business Review, 223-230.

Fama, E. (1970). Efficient Capital Markets: A Review of Theory and Empirical Work. Journal of Finance, 383-417.

Gilani, S. N. (2014). Testing the Weak Form Efficiency of Islamabad Stock Exchange. Developing Country Studies.

Gimba, V. K. (2012). Testing the Weak-form Efficiency Market Hypothesis: Evidence from Nigerian Stock Market. CBN Journal of Applied Statistics, 117-136.

Gupta, N., \& Gedam, A. (2014). Testing of efficient market hypothesis: a study on Indian stock market. Journal of Business and Management, 245-273.

Levine, R. (1997). Financial Development and Economic Growth: Views and Agenda. Journal of Economic Literature, 688-726. 
96 THE BATUK : A Peer Reviewed Journal of Interdisciplinary Studies $\quad$ Vol. $6 \quad$ Issue No. $2 \quad$ July 2020 ISSN 2392-4802

Mensah, T., Adom, P. H., \& Pomaa-Berko, M. (2014). Does Automation Improve Stock Market Efficiency in Ghana? African Review of Economics and Finance, 69101.

Mlambo, C., \& Biekpe, N. (2007). The efficient market hypothesis: Evidence from ten African stock markets. Investment Analysts Journal, 66-78.

Ntim, C. G., Opong, K. K., \& Dunbolt, J. (2007). An Empirical Re-Examination of the Weak-Form Efficient Market Hypothesis of the Ghana Stock Market Using Variance Ratio Tests. African Finance Journal, 115-124.

Ojo, O., \& Azeez, B. (2012). A Test of Strong-Form Efficiency of the Nigerian Capital Market. Business Systems Review.

Okpara, G. C. (2010). Analysis of Weak Form Efficiency on the Nigerian Stock Market: Further Evidence from GARCH Model. The International Journal of Applied Economics and Finance, 62-66.

Oladapo, F. \&., \& Ayowole, A. (2013). An Empirical Analysis of Efficiency of the Nigerian Capital Market', Research Journal of Finance and Accounting.

Osamah, M. A., \& Ding, D. (2007). A New Variance Ratio Test of Random Walk in Emerging Markets. Financial Review, 303-317.

Osei, A. K. (2002). Asset Pricing and Information Efficiency of the Ghana Stock Market, AERC Research Paper 115. African Economic Research Consortium, Nairobi.

Potocki, T., \& Swist, T. (2012). Empirical Test Of The Strong Form Efficiency Of The Warsaw Stock Exchange: The Analysis of Wig 20 Index Shares, South-Eastern Europe. Journal of Economics.

Simon, D., \& Laryea, S. (2004). Testing the efficiency of selected African markets. Finance India, 553-571. 